\title{
First report of a phytoplasma associated with an axillary shoot proliferation disease in papaya in India
}

\author{
R. Verma, D. Mungekar, P. Gaikwad, S.P.S Tomer and V.V. Datar
}

Indian Agricultural Research Institute (IARI), Regional Station, Agricultural College Estate, P.O. Shivajinagar, Pune- 411005, India

*E-mail: rajverma0762@gmail.com

Papaya (Carica papaya) is a popular fruit crop widely cultivated in India and affected by a number of phytoplasma diseases worldwide such as dieback (Guthrie et al., 1998; Gera et al., 2005; Arocha et al., 2007a; Rao et al., 2011), bunchy top (Arocha et al., 2007b) and yellow crinkle and mosaic (Guthrie et al, 1998). During December 2011, phytoplasma-like symptoms were observed in a papaya field at the IARI Regional Station, Pune, Maharashtra, India. These included bright yellowing of the upper young leaves followed by drying of upper leaves, proliferation of axillary shoots, reduction in leaf size and interveinal chlorosis (Fig. 1). The symptoms observed in the papaya fields of Pune, Western India differed from those associated with the dieback disease of papaya reported from Gorakhpur, Western India (Rao et al., 2011) in the lack of tip necrosis of leaves and dieback symptoms.

Leaf samples from four symptom-bearing plants and four symptomless plants were collected and total genomic DNA was extracted from leaf midribs and petioles $(100 \mathrm{mg}$ ) using the DNeasy Plant Minikit (Qiagen, Germany). Two sets of universal primers were used to amplify the phytoplasma $16 \mathrm{~S}$ rDNA by nested PCR; this included direct PCR with primers $\mathrm{P} 1 / \mathrm{P} 7$ that prime a region of approximately $1.8 \mathrm{~kb}$, followed by nested PCR with primers R16mF2/R16mR1 (Gundersen \& Lee, 1996) that flank a $1.2 \mathrm{~kb}$ genomic fragment. A phytoplasma-infected Catharanthus roseus plantmaintained in the glasshouse at the IARI Regional Stationwas used as the positive reference control. Three representative nested PCR products were purified (Wizard SV Gel and PCR Clean Up System, Promega, USA) and directly sequenced (Genombio Technologies, Pune, India). A phylogenetic tree based on the consensus and reference phytoplasma $16 \mathrm{~S}$ rDNA sequences was constructed by using the Neighbor-Joining method and 1000 replicates for the bootstrap values (MEGA5, USA). The evolutionary distances were computed using the Maximum Composite Likelihood method and are reported as number of base substitutions per site. A nested PCR product of approximately $1.2 \mathrm{~kb}$ corresponding to the phytoplasma $16 \mathrm{~S}$ rDNA was amplified from the four infected papaya plants (Fig. 2). No PCR band was observed for the symptomless papaya plants. The partial 16S rDNA sequence of the three representative phytoplasma isolates shared $100 \%$ sequence identity with each other, while the BLAST analysis of the consensus sequence (GenBank Accession No. JQ346525) revealed 99\% sequence identity with that of phytoplasmas of group 16SrII ('Candidatus Phytoplasma aurantifolia') including the Ethiopian papaya phytoplasma (DQ285659)
(Fig. 3).

In India, phytoplasmas of group $16 \mathrm{SrI}$ ' $\mathrm{Ca}$. Phytoplasma asteris' and 16SrII (Rao et al., 2011) have been associated with dieback disease of papaya. However, the 16SrII phytoplasma associated with axillary shoot proliferation clearly differs from the $16 \mathrm{SrII}$ dieback phytoplasma in symptomatology and occurrence within Western India. This suggests that there may be two different 16SrII phytoplasma eco-strains able to infect the same host in the country. To our knowledge, this is the first record of 16SrII group ' $\mathrm{Ca}$. Phytoplasma aurantifolia' associated with an axillary shoot proliferation disease of papaya in India.

\section{Acknowledgements}

The authors acknowledge Mr. Pandurang Kolekar, Research Fellow, Bioinformatics Centre, University of Pune, India for his contributions to the phylogeny analysis.

\section{References}

Arocha Y, Bekele B, Tadesse D, Jones P, 2007a. First report of a 16SrII group phytoplasma associated with die-back diseases of papaya and citrus in Ethiopia. Plant Pathology 56, 1039. [doi:10.1111/j.1365-3059.2007.01633.x]

Arocha Y, Pinol B, Lopez M, Miranda I, Almeida R, Wilson M, Jones P, 2007b. Bunchy top symptom of papaya in Cuba: new insights. Bulletin of Insectology, 393-394.

Gera A, Mawassi M, Zeidan A, Spiegel S, Bar-Joseph M, 2005. An isolate of 'Candidatus Phytoplasma australiense' group associated with Nivun Haamir dieback disease of papaya in Israel. Plant Pathology 54, 560. [doi:10.1111/j.1365-3059.2005.01236.x]

Gundersen DE, Lee IM, 1996. Ultrasensitive detection of detection of phytoplasma by nested-PCR assays using two universal primer pairs. Phytopathologia Mediterranea 35, 144-151.

Guthrie JN, White DT, Walsh KB, Scott PT, 1998. Epidemiology of phytoplasma-associated papaya diseases in Queensland, Australia. Plant Disease 82, 1107-1111. [doi:10.1094/PDIS.1998.82.10.1107]

Rao GP, Chaturvedi Y, Priya M, Mall S, 2011. Association of a 16SrII group phytoplasma with dieback disease of papaya in India. Bulletin of Insectology. 64 (Supplement), S105-106.

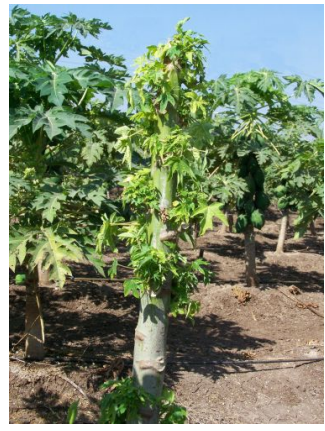

Figure 1

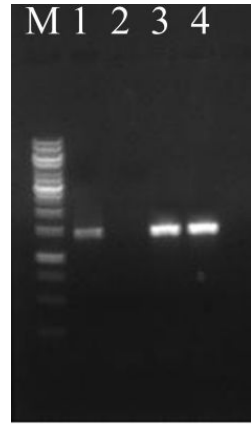

Figure 2

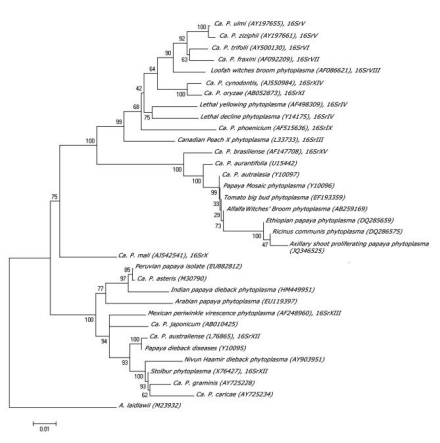

Figure 3

To cite this report: Verma R, Mungekar D, Gaikwad P, Tomer SPS, Datar VV, 2012. First report of a phytoplasma associated with an axillary shoot proliferation disease in papaya in India. New Disease Reports 25, 18. [doi:10.5197/j.2044-0588.2012.025.018]

(c) 2012 The Authors

This report was published on-line at www.ndrs.org.uk where high quality versions of the figures can be found. 